\title{
Lost and found in Ireland; how a data label resulted in a postal delivery to Metriocnemus (Inermipupa) carmencitabertarum (Orthocladiinae)
}

\author{
Declan A. Murray
}

Freshwater Biodiversity Ecology and Fisheries Research Group, School of Biology and Environmental

Science, University College Dublin, Belfield, Dublin 4, Ireland.

E-mail: declan.murray@ucd.ie

Langton and Cobo (1997) erected the subgenus Inermipupa within Metriocnemus (Orthocladiinae) and described all life history stages of Metriocnemus (Inermipupa) carmencitabertarum from specimens obtained in Spain and Portugal in 1989. The pupa had been known prior to the description of the new species and was included in Langton (1991) as "Orthocladiinae gen.? sp.? Pe3". The first record outside the Iberian Penninsula was from a collection of the distinct pupal exuviae in October 1998 on the Azorean island of Terceira (Murray et al. 2004). Since then and more recently the species has been recorded from The Netherlands (Kuper and Moller-Pillot 2012), England (Langton 2012) and from numerous pupal exuviae and adults collected in Ireland in March 2012 (Murray 2012). Subsequently on 17 October 2012 I collected some adults and pupal exuviae from a rain-filled barrel in the yard at my home near Ashbourne, Co. Meath and placed them in alcohol in a SARSTEDT $2 \mathrm{ml}$ plastic vial to send to P. H. Langton (PHL) in Northern Ireland who had requested some specimens for his personal collection. With an appropriate data label in the vial (Fig. 1) detailing species name, date and site of collection etc., it was packed and posted to PHL in Coleraine, Co. Derry, Northern Ireland. However, when the package was delivered the vial was missing - it had been separated from the package. When PHL reported this loss on 22 October a second vial with more specimens was prepared and posted. This time delivery was successful.

But that was not the end of the affair. Five months after the loss of the vial from the first mailing, in March 2013 my postman showed me a "Royal Mail" envelope and, pointing to the address label, asked if could be for me. It was - the envelope contained the original vial that was posted to PHL in October 2012. The specimens were undamaged and intact. The back of the envelope (Fig. 2) was stamped "Found opened or damaged and officially secured" and initialled "N.I.M.C." (Northern Ire-

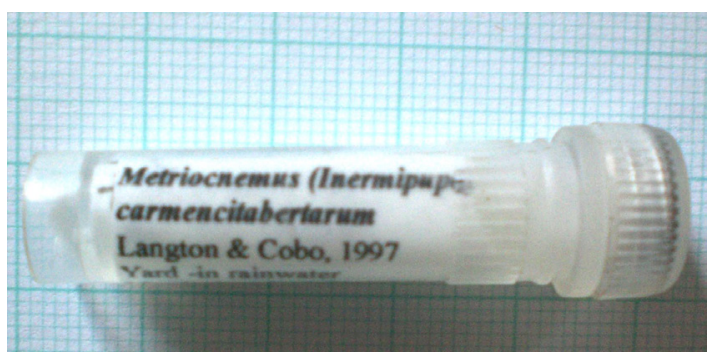

Figure1. The internally labelled vial that was lost in the post

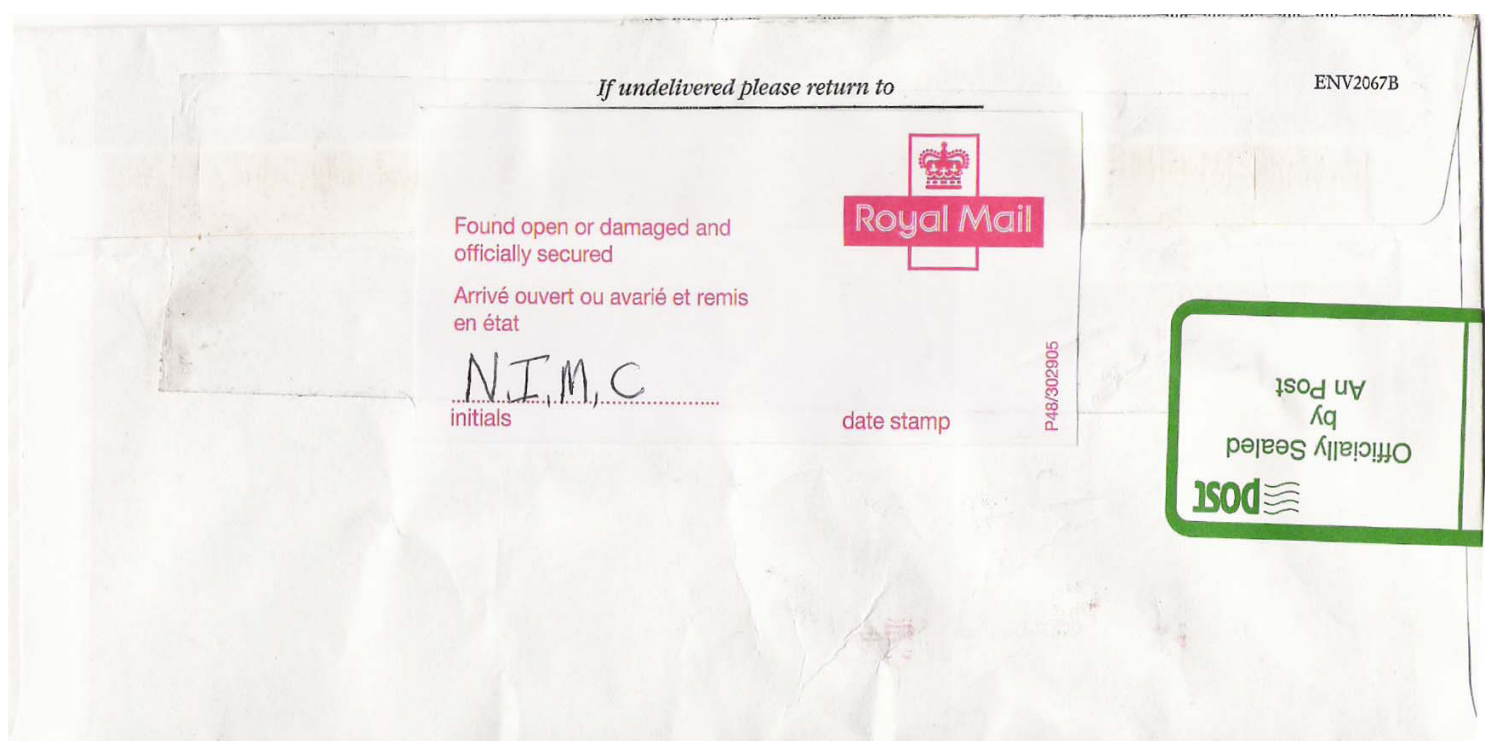

Figure 2. Back of envelope from the Northern Ireland Royal Mail Centre (N.I.M.C.) also showing the Irish "An Post" seal. 
land Mail Centre). The vial had obviously been found in the Northern Ireland Mail Centre where, on examination, an astute official read and copied relevant data information from the label in the vial on to the envelope in an attempt to return it through the postal system to the original sender.

The hand written address on the envelope (Fig. 3) read:

Metriocnemus carmencitabertarum

Langton \& Cobo 1997,

yard - in rainwater,

Meadesbrooke, Ashbourne,

Co Meathe IGR

To which the Northern Ireland official added "R.O.I” (Republic of Ireland)

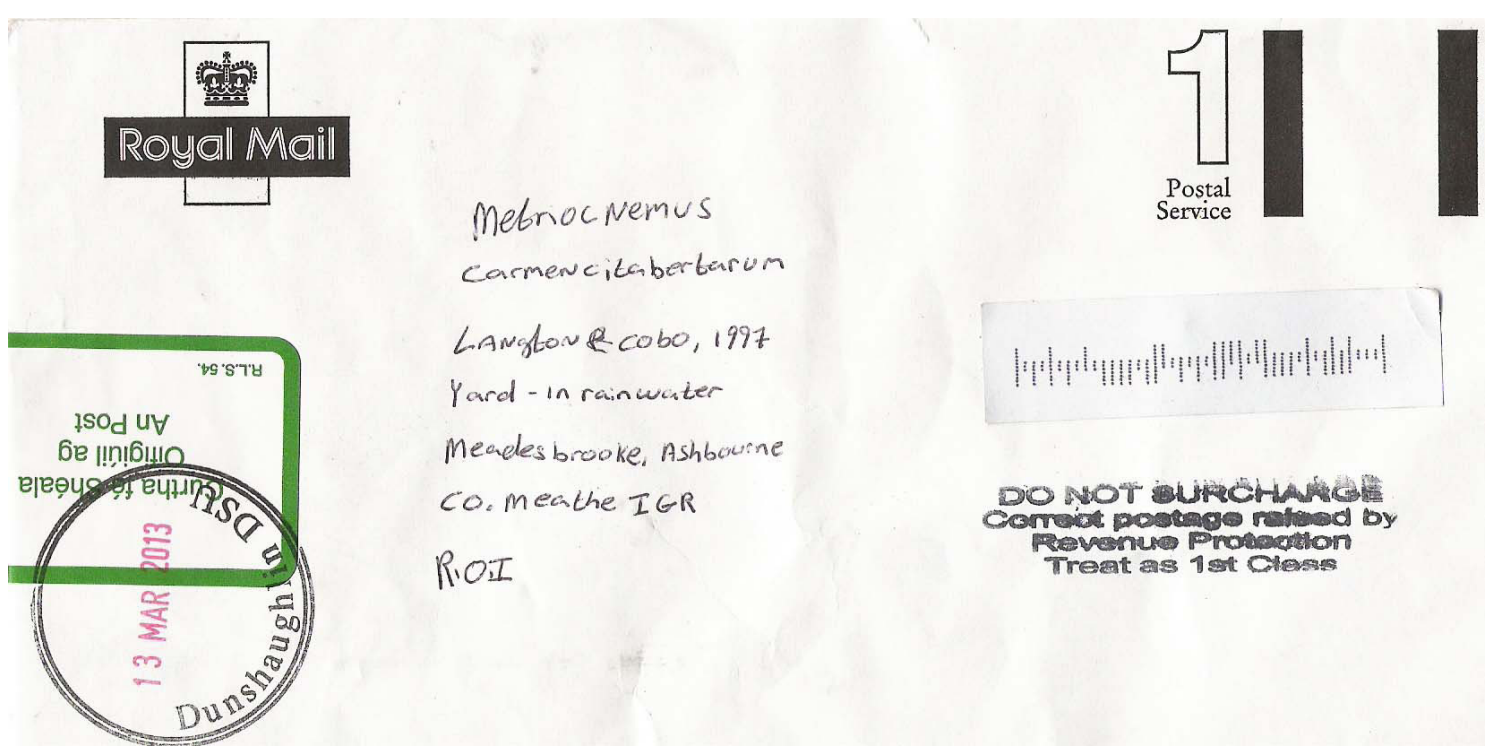

Figure 3. Front of the Royal Mail envelope that contained the returned vial addressed to "Metriocnemus carmencitabertarum" and showing the An Post date stamp 13 March 2013.

On its return journey the envelope containing the original vial had also been opened, examined and resealed by an official of An Post, the Irish Postal Service, at the Dunshaughlin sorting office since it bore a label "Officially Sealed by An Post and was date stamped 13 March 2013.

Credit is due to the official in the Northern Ireland Mail Centre for his/her initiative in copying the label information in the alcohol-filled vial and to the officials in the postal service in the Republic of Ireland and to my postman who recognised the possibility that the peculiar name and address for such an unusually named individual as "Metriocnemus carmencitabertarum" must have been linked with the entomologist who lived at "Meadesbrook" !

\section{References}

Kuper, J. and Moller Pillot, H. 2012. Metriocnemus carmencitabertarum, een nieuwe Dansmug voor Nederland (Diptera: Chironomidae). - Nederlandse Faunistische Mededelingen 38: 49-54.

Langton, P. H. 1991. A Key to the Pupal Exuviae of West Palaearctic Chironomidae. Privately Published by the author, 386p.

Langton, P. H. (2012) Metriocnemus (Inermipupa) carmencitabertarum Langton and Cobo (Diptera: Chironomidae) in England. - Dipterists Digest 19: 141.

Langton, P. H. and Cobo, F. 1997. Metriocnemus (Inermipupa) carmencitabertarum subgen. n., sp. n. (Diptera: Chironomidae) from Spain and Portugal. - Entomologist's Gazette 48: 263-271.

Murray, D. A. 2012. First record for Ireland of Metriocnemus (Inermipupa) carmencitabertarum Langton 
and Cobo, 1997 (Diptera: Chironomidae, Orthocladiinae). - Bulletin of the Irish Biogeographical Society 36: 3-7.

Murray, D.A., Hughes, S.J., Furse, M.T. and Murray, W. 2004. New records of Chironomidae (Diptera: Insecta) from the Azores, Macaronesia. - Annales de Limnologie. International Journal of Limnology. 40: $33-42$. 